\title{
Lusioersily
}

\section{ICT Interface Design for Ageing People and People with Dementia}

Wallace, J., Mulvenna, M., Martin, S., Stephens, S., \& Burns, W. (2010). ICT Interface Design for Ageing People and People with Dementia. In M. Mulvenna, \& CD. Nugent (Eds.), Supporting People with Dementia Using Pervasive Health Technologies (pp. 165-188). Springer. https://doi.org/10.1007/978-1-84882-551-2

Link to publication record in Ulster University Research Portal

Published in:

Supporting People with Dementia Using Pervasive Health Technologies

Publication Status:

Published (in print/issue): 01/01/2010

DOI:

10.1007/978-1-84882-551-2

\section{Document Version}

Publisher's PDF, also known as Version of record

\section{General rights}

Copyright for the publications made accessible via Ulster University's Research Portal is retained by the author(s) and / or other copyright owners and it is a condition of accessing these publications that users recognise and abide by the legal requirements associated with these rights.

\section{Take down policy}

The Research Portal is Ulster University's institutional repository that provides access to Ulster's research outputs. Every effort has been made to ensure that content in the Research Portal does not infringe any person's rights, or applicable UK laws. If you discover content in the Research Portal that you believe breaches copyright or violates any law, please contact pure-support@ulster.ac.uk. 


\title{
Chapter 11 \\ ICT Interface Design for Ageing People and People with Dementia
}

\author{
Jonathan Wallace, Maurice D. Mulvenna, Suzanne Martin, Sharon Stephens, \\ and William Burns
}

\begin{abstract}
Ageing population trends, rising healthcare costs and social and digital inclusion are all factors in the background to the problem of older adults interacting with technology. Approaches to address "physical accessibility" and "access to technology" issues, as well as training for existing systems are evident, yet a usability issue still prevails. The primary aim of this chapter is to provide an overview of the research and literature and discuss the differing contexts in which older people and people with dementia interact with computerised systems and their associated issues.
\end{abstract}

\subsection{Introduction}

In Europe by 2050, it is estimated that one-third of Europe's population will be over 60 . The number of "oldest old" aged $80+$ is expected to grow by $180 \%$ (Eurostat 2002). For example, in 1951, there were 300 people aged 100 and over in the UK. By the year 2031, it is estimated that this figure could boom to 36,000 (BBC News 2007).

Governments are naturally concerned by these population trends, particularly with the associated rise in the cost of health care provision, due to the corresponding increase in chronic diseases such as diabetes, asthma, arthritis, heart failure, chronic obstructive pulmonary disease, dementia and a range of disabling neurological conditions. There are 700,000 people living with dementia in the UK today, a number forecast to double within a generation. Twenty-five million people, or $42 \%$ of the UK population, are affected by dementia through knowing a close friend or family member with the condition. One in three over 65 years will die with someform of dementia. (Alzheimer's Research Trust 2009). Indeed, the

\footnotetext{
J. Wallace $(\varangle)$

TRAIL Living Lab, School of Computing and Mathematics, Faculty of Computing and Engineering, University of Ulster, Jordanstown, UK e-mail: jg.wallace@ulster.ac.uk
} 
World Health Organisation (WHO) has identified that such chronic conditions will be the leading cause of disability by 2020 and that, if not successfully managed, will become the most expensive problem for health care systems (World Health Organisation 2005).

However, charitable organisations are particularly concerned with the social factors, where this section of the population can find themselves increasingly excluded from society in a number of ways. In the report by the Digital Inclusion Panel (2004) aspects such as poverty, rural location and ethnicity were all cited as important factors contributing to exclusion from society. Initiatives have been trialled, which give free access to computer technology for the public at large. Public libraries have free access, for members, to the Internet. Access to technology is no longer a barrier to the older person as they are beginning to purchase their own PCs. A survey in 2003 found that " $50 \%$ of people aged 60- to 64-years-old owned a computer with $37 \%$ online at home, and that they represented 12\% of Internet users in the UK" (Jeffrey 2003). Indeed a recent survey by Hitwise a subsidiary of Experian in the UK has indicated that the aged 55+, the so-called silver surfers, are about to bypass the 35to 44-year olds as the demographic age group representing the largest share of the UK Internet visits. Those aged 55+ represented $22.0 \%$ of the UK visits to all categories of websites in the 4 weeks to 12th May 2007, which was up 54\% since 2005 and $40 \%$ since 2006 . This compares to $23.5 \%$ of Internet visits from 35-to 44-year olds. It is interesting to note that this increase has come from both rich and poor alike. The Experian Mosaic classification allocates every household in the UK into 1 of 61 Types and 11 Groups. The Experian Mosaic groups Twilight Subsistence (pensioners subsisting on meagre incomes) and "grey perspectives" (pensioners enjoying retirement with savings to supplement their pensions) have both increased their online footprint. Internet visits from Twilight subsistence are up 29\% over the past 2 years and visits from grey perspectives are up 30\% (Hopkins 2007).

For the purposes of this chapter we utilise Ben Schneiderman's definition of the human-computer interface which takes into consideration the interface in its widest sense, not just with regard to screen design - "human-computer interface refers to the way a person experiences the computer, its application programmes, hardware components, output devices and functionality. It includes all aspects of the human's experience from the obvious ones of screen layout and selection options as well as input and output devices, reliability and accessibility." (Schneiderman 1996).

The older adult will be exposed to technological interfaces through necessity as technology moves on and becomes impossible to avoid. The increase in assistive devices in homes will also drive increased interaction with computer systems. The UK Government has become intent on moving towards a digitally inclusive society, measuring progress through results such as those cited in the 2004 report entitled "Enabling a digital UK" (Digital Inclusion Panel 2004) such as the finding that "five times more homes are connected to the Internet than in 1999" and "70\% of government services are available online". For the purposes of the report Digital Inclusion is defined as "using technology as a channel to improve skills, to enhance quality of life, to drive education and to promote economic well being across all elements of society." (Digital Inclusion Panel 2004). 
While physical accessibility has been addressed to some extent, there has been little or no attempt to rethink interface concepts to accommodate the older user and to reflect their specific problems with formation of suitable mental model for systems. The "Your Guide" system of free-standing public access kiosks was piloted in 2000-2001 by the UK Government and Consignia. This information kiosk was an effort to boost the flagging post offices and to help the UK Government deliver on its commitments to provide e-information to all (Keates and Clarkson 2003). Initially some physical requirements were identified which needed to be changed. Having been designed mostly by men, the pilot kiosks were generally too high for older women and others, to see the screen properly; the screen was too small to accommodate the larger size fonts needed for those with impaired vision. This resulted in only a few lines of text being displayed at one time. There was an increased need for scrolling, which had its own associated problems for the less agile fingers. The need to use both hands to operate the system was another obstacle, for those with walking difficulties, where one hand was needed to hold a walking stick or other walking aid. Lessons have been learned about physical limitation of older people but little attention has been paid to the other facets of decline due to natural ageing.

The functional needs of the older user also vary greatly from other sectors of users since most of the older users will not be using technology for business or work related tasks. They may wish to book cheap flights; after all they have more leisure time than the working population. They may see a greater need to communicate with family and friends across the world, e.g. sending e-mail to family members. Grandparents may be driven by the desire to see pictures or indeed video of a new grandchild, as a reason to access technology and overcome their initial fears. Fit older adults today will become progressively less able with age and many will live in a technologically supported living environment. The challenge for ubiquitous and pervasive computing in such supported living environments is in managing a sophisticated and dynamic perspective on computer-mediated interactions with human beings, without intruding unnecessarily into their lives. This is what is described as the notion of calm (Weiser 1991), where the computing resources quietly modify themselves to suit the needs of the user. An intuitive interface design would also be able to span different technologies and may be of use in the "Smart-Home" environment. This would in turn help to decrease healthcare costs, as more people would be enabled to live on longer their own.

Background research findings indicate that more research is needed to establish the main problems or obstacles that discourage older adults from using computerised facilities and systems. Few attempts have been made to redesign the interfaces with focused functionality and using more meaningful interface design to accommodate the older user. The primary emphasis to date has been on hardware issues, physical disability accessibility, web design and training for existing interfaces. A solution that enables a more intuitive information transfer between system and this user group could then be extended to span other user groups and various contexts of interaction. Many people over the age of 60 have difficulty using standard computer and communication devices. Even when the technology is made readily available to them, the uptake rate for making use of these facilities is poor. A technology rich 
environment is becoming more and more commonplace and older members of society appear to have convinced themselves that they will never be able to cope with the changes. Initially they are frightened and subsequently find the standard interfaces of the devices confusing and difficult to understand. Not utilising this advantageous technology is, not only decreasing the effectiveness of assisted living systems, but is depriving older people of opportunities to improve their quality of life and reducing their opportunity for social inclusion.

The remainder of this chapter is laid out in the following sections. In Section 11.2, we present our overview of the research and literature grouped into five areas:

- Age-related issues: targeting the issues raised for HCI and interface design in respect of physical and cognitive needs of the older population.

- Special requirements related to the user group: requirements beyond those of the physical needs of the older person, such as the diversity of the group and special difficulties in communicating requirements between the user group and the designer.

- Emerging approaches: new approaches to design for this user group.

- Broader technological perspective: other technological areas than the standard software and web applications - ubiquitous and pervasive systems as well as assistive technologies.

- Specific interface design issues for people with dementia.

Section 11.3 briefly discusses other associated issues and Section 11.4 presents a discussion on the review findings and draws conclusions.

\subsection{Ageing and Interface Design}

Ian Stuart-Hamilton describes chronological age as an arbitrary figure since there is no specific time when age happens (Stuart-Hamilton 1994). It is agreed amongst professionals in gerontology that 60-65 is the "Threshold age" when the signs of ageing become more distinct. Government too, tends to refer to those over 60 as older adults. This may be because it is the age most people begin retirement and have reduced activity. It is worth bearing in mind though that age is a natural, gradual process and losses due to age can begin in early adulthood and only become more obvious in the $60+$ years.

According to Stuart-Hamilton (1994), ageing affects the sensory systems of the older adult. Sight deficiencies include the loss of acuity (the ability to focus on detail) especially in poor contrast or dim light. As vision deteriorates it becomes more difficult for the eyes to recover from glare. Older people require a longer time to process visual stimuli and also suffer from a narrowing of field of vision or even loss of peripheral vision. Sight is not the only sense affected by age; hearing is compromised too. Hearing losses include the loss of the ability to recognise high-frequency sounds and the inability to distinguish the direction of source of a 
sound. Hearing distortions are also more common with age; e.g. tinnitus, a ringing in the ears.

Other senses are affected by age but they do not have the same affect on intellectual skills as vision and hearing. Age deficiencies are more apparent when several functions must be used at once or when the message to the brain is a more complex message. Focusing of attention is diminished by age, and processes of the brain are generally slower (Stuart-Hamilton 1994). Since there is argument regarding exactly when ageing begins and the differences between young old and older old (which may have bearing on the service type the person wants to access and the mode that is most appropriate), for the purposes of this chapter we will define the use of the term older adult as persons aged 60-80.

The literature we have reviewed for this chapter although very varied in focus, facilitated a grouping into five broad categories:

- Age-related issues: targeting the issues raised for HCI and interface design in respect of physical and cognitive needs of the older population.

- Special requirements related to the user group: requirements beyond those of the physical needs of the older person, such as diversity of the group and special difficulties in communicating requirements between the user group and the designer.

- Emerging approaches: new approaches to design for this user group.

- Broader technological perspective: other technological areas than the standard software and web applications - ubiquitous and pervasive systems as well as assistive technologies.

- Specific interface design issues for people with dementia.

\subsubsection{Age-Related Interface Issues}

Many of the papers we have reviewed deal with the physical, psychological and other age-related issues which must be considered in interface design. While the usual guidelines of HCI (human-computer interaction) are to be applied, it should be considered which age-related issues apply and how HCI techniques can allow for these. Older adults are subject to changes in their intellectual skills in later life. The physical degradation and damage through age, to the Hippocampus especially, affects the ability to learn through exploration (Stuart-Hamilton 1994). This type of learning is associated with understanding computer interfaces, and is how the user understands the user interface for web and software applications. Older adults are still able to learn but in a different way, as discussed by Zajicek (2001). Zajicek looks at physical and other issues which affect interface design. Physical changes such as failing eyesight, diminishing intellectual skills and memory loss are the main issues which affect how a user interacts with a system. The memory loss associated with age means that the user is less able to cope with complex navigation structures or long lists of instructions. Care must be taken to reduce the load on the memory by using short messages, for example. Although learning is more difficult for the 
older person it is still possible. Different approaches to interface design should be used which result in interfaces which do not rely so heavily on exploratory investigation on the part of the user. Zajicek also points to the dynamic nature of the requirements for this user group. Tiredness and state of health or mind can have a significantly greater effect on the performance of these users when compared to other user groups. Grouping the users under the one term "older users" is misleading. It gives the impression of a homogenous group of people. Interestingly, a larger degree of diversity is found in this group than younger groups. Therefore the requirements cannot be regarded as a standard static set for all older users. One very interesting aspect that Zajicek points out is that although younger users and technophiles emphasise the convenience of computers and Internet as a main advantage, older users are not motivated by that argument. They may prefer a trip to the shop to talk to the shop keeper or to just get out of the house. This motivation can have a real influence on how well a person performs. Older people will accept technology but weigh up whether it is worth the effort; after all they may have to learn how to operate the keyboard before they master the Internet. Zajicek suggests that, to make systems and hence interfaces easier for older or sight restricted users, functionality should be reduced. While her suggestion is a valid one, it could be argued that a more universal approach to design might also be appropriate.

Hawthorn (2000) also discusses these age-related issues and the implications for HCI. Examining the factors, he agrees that because cognitive skills are affected by age, the load on the memory should be kept to a minimum. A simple, structured interface is important in order that all the cognitive powers can be concentrated on the task and not wasted on understanding the interface and the interaction process. His research suggests numerous tactics for increasing the usability of the interface through simple HCI techniques. His findings suggest that older users need greater contrast between text and background than other users (coloured text on coloured backgrounds slows the reader). He placed special emphasis on text size and recommended the use of simply structured layouts to increase clarity and consistency.

Investigations by van Horen et al. (2005) into instruction manuals also suggest some techniques to assist older people's comprehension of text and subsequent task performance. Older people require more time than average to read and digest text information, and they follow instructions better when they are segmented. He also emphasised, (because of short-term memory load restrictions), the importance of listing the most informative items first. Another important aspect he points out is feedback. A designer should always inform a reader what should happen or what he/she should expect to experience. These steps can improve task performance for the older user. Hawthorn also stresses the importance of target size. Large target size facilitates not only those with poor eyesight but also the less accurate mouse clicking reported with older users. Hawthorn makes some suggestions for design to facilitate those with impaired hearing. Lower sound frequencies are more appropriate for the older person. He has concluded, through this research, that even those with a high level of computer expertise will suffer from age-related barriers to continuing use of computers in later life. Expertise is generally restricted to a specialised field. As 
people age they experience difficulty in transferring their expertise to a new context. People currently approaching retirement age will have at least some exposure to computer systems. They will not necessarily be able to transfer their knowledge to a new system of the future. They will find it equally difficult to acquire the necessary new skills. The same age-related barriers to understanding a new system will exist, as for other older people, especially if the new system requires formation of a new mental model.

Feedback is an important facet of interface design and can play a significant role in error reduction and the visibility of a system, according to Norman (1992). Visibility is best explained by saying, "the better the visibility, the more obvious are the actions you need to take to achieve your goal." Feedback itself can be delivered using different modes, visual (sight), auditory (sound) and haptic (touch). Systems and interfaces use various types of feedback as part of their design.

Jacko et al. (2004) found that both novice and experienced older users can benefit from improved feedback combinations more significantly than the younger user groups. Although the experienced user performed well with drag and drop tasks, they also benefited from multimodal feedback. Their experiments used various combinations of haptic, visual and auditory modes of feedback. Their test groups included older and younger users of different computer experience levels. The results suggested that auditory feedback caused the greatest improvement in performance error reduction. Jacko recommends the inclusion of auditory feedback with or without any other feedback will prove beneficial in improving the manipulation accuracy of the older user. Their testing was using only a drag and drop scenario and further experimentation may be needed to prove the finding for other types of tasks.

\subsubsection{Special Requirements Relating to Older People}

In Zajicek's work, as discussed earlier, it was suggested that older people had different motivations for embracing technology. Systems may not have been explained to them in terms that they understood, and there were subsequent difficulties in forming a coherent mental model to aid understanding. This is not the only obstacle to "uptake" by the older population. Older people have a different perception to technology than younger adults, believing that it is not meant for them, or not of any use or relevance to them. Due to the distribution of wealth (Banks et al. 2006), which indicates that those with the most wealth are those aged 65-69 (i.e. retirement age) the financial barriers may not be as prohibitive as one might have thought. Attitudes to spending in younger generations and the current economic climate may also affect the distribution of wealth in future years. Technology is becoming more affordable, and free access is often provided in libraries and other centres.

Research by Patricia Wright et al. (2000) on text entry methods for handheld devices which included older users, suggests older people will accept new technology. As part of research to investigate whether users of different ages preferred on screen entry or keyboard entry of text, $50 \%$ of the older user group reported that they 
would use the PDA (Personal Digital Assistant), if they had won one in a competition. Wright's claims would tend to dispel the idea that older users will not engage with new technology.

Failing eyesight and motor skills are measurable physical effects of ageing, but it is evident from reviewing the research that simply enlarging text and minimizing functionality does not provide a complete and acceptable solution. The user group in question, i.e. the over 60s are not a homogenous group. They have different motivations and requirements beyond those which meet their physical needs. Time and life experiences lead this group to be the most diverse of all. Couple those distinctions with the complication of differing levels of computer expertise and it becomes clear that defining requirements for this user group is complicated.

According to Zajicek and Brewster (2004), participants at the 2002 HCI conference agreed that the "Dynamic Diversity" was one of the most important characteristics of the group. In the editorial they cite, amongst others, two important contributions to the research discussed at the conference, which have concentrated on the special difficulties encountered when dealing with older users: Eisma et al. (2004) and Lines and Hone (2004). Zajicek and Brewster conclude that a more sensitive and social approach is required and that the general design and data gathering methodologies must be adapted to be effective in this context. One important observation was that older people don't regard efficiency of performing a task as important as getting the task completed. The question of how to gather requirements from such a diverse group is examined.

The work of the researchers on the UTOPIA (Usable Technology for Older People - Inclusive and Appropriate) project, a collaborative research project amongst several Scottish universities, is discussed in a paper by Eisma et al. (2004). Their findings centre on how best to engage and deduce requirements from groups of older people and the disabled. They find that preconceptions are a major factor, old people might think they are too old to learn, or that they have no use for new technology. Since they don't have a clear understanding, having maybe never used any similar systems before, it is difficult for them to know what they require. It is also difficult for them to communicate what requirements they do have to, generally younger and technically minded designers. Usual methods must therefore be adapted for requirements gathering. Eisma et al. found that the social aspects of requirements-gathering encounters were very important. Loneliness, eagerness to please, fear of offending and cautious answers were all typical attitudes of the older adults involved in the UTOPIA research groups. The researchers tried various methods of requirements gathering. Focus groups proved difficult, if there were too many participants. Older people tended to stray from the discussion topic. When questionnaires were used it was found that the answers reflected a high level of noncommittal responses. The recommendations were that focus groups should be kept small, questionnaires worded to force more commitment by the respondent and the use of hands-on examples and visual aids to increase understanding.

Lines and Hone (2004) also document the difficulties encountered in requirements gathering for this user group. The focus group method is generally recommended as an effective and cheap method of requirements gathering, used in this case to gather requirement regarding an IDAS (Interactive Domestic Alarm System). 
It soon became clear to them that executing this method, as for other groups, had its difficulties. A focus group is intended to involve a large number of users at once to maximise time. This was unsuitable as too many participants only encouraged less useful discussion on the topic and more social interactions. Individual older people require a lot more attention and direction than the younger counterparts. The loose structure which is intended to promote free flowing ideas was too vague for the participants and it was found even semi-structured sessions had improved results. As a result they agree with Eisma et al. in suggesting the use of small highly structured focus group sessions. Where a deeper level of information is required individual interviews should be conducted. Any focus group conducted must only be done when the researcher himself has a clear understanding of the topic area, and can subsequently structure the session appropriately. This method would not be usable in an unknown domain. However the researchers, Lines and Hone, do not recommend completely excluding the older user from the process. It was evident from their findings that the older person still had a valuable input. The list of requirements provided by the carers of the users in the study, did not reflect the requirements that the older persons provided themselves. If those who have expertise and empathy with this group of people have difficulty defining requirements, how much more difficult is it for those who are primarily concerned with the technology to estimate appropriate requirements. It is clear that existing standard methods generally used must be adapted to gather appropriate user requirements.

Zajicek and Brewster refer to the study by Keates and Clarkson (2003) into the designing of an information kiosk for older users. They had found that $45 \%$ of the target user group could not use the first design of kiosk. This was due to mainly hardware issues, such as screen size, kiosk height and mobility issues. Once these physical issues were resolved, the interface itself also proved problematic. Use of inappropriate icons and inconsistent interface design paradigms caused difficulties for the older user in forming an appropriate mental model. They conclude that designers for older users must use some type of user-centred approach to design. The younger designer cannot design adequately for those outside his experience using standard methodologies. They also say that these users are the most likely not to conform to any standard user requirement assumptions.

During their research, Eisma et al. found Scottish businesses and industries to be uninterested in the older user group. Older people are currently a small part of the buying public and are less likely to buy new technology. Therefore they did not consider a business opportunity existed. Costs of specialist products are usually higher than mainstream products and so for systems to be available at a reasonable price they must have general appeal. A solution specific to one type of user has much less marketability than one generally accepted.

\subsubsection{Emerging Approaches}

Hawthorn (2003) agrees that the difficulty with making a system universally accessible is that simplification results in a system that no longer meets the required functionality of the experienced user. To satisfy a universal audience fully, a wide 
range of functions would be needed. To test the universal nature of "good design for older user" Hawthorn examines the design process of the previously developed "SeniorMail" system, an e-mail system developed specifically for a group of elderly users. He based his choice of which features to include and which to avoid primarily on literature research. He argues that other means of requirement gathering for such a wide diversity of user could not capture accurately the requirements. For example, general information on the range of "visual acuity" in the older population led him to the choice of font size, etc. Other features mirror those recommended in Hawthorn's earlier papers (2000), i.e. large targets, large buttons, colour schemes, simple navigation structure. He concludes that existing systems must be simplified to make them more usable for the elderly. He argues that it would be difficult to produce a system that would not exclude older users and yet remain attractive to younger more proficient users. While it may be possible to redesign web pages to accommodate a universal audience, this would not be able to be achieved in a programme software environment. Hawthorn concludes that universal appeal is difficult to achieve and that "senorised" versions of systems should be produced in the form of a simplified version of the real thing, which may be viewed as a training version of the full package.

A similar project "Cybrarian" (Dickinson et al. 2005) produced a specially designed e-mail system, rather than a redesign of the Windows version. The design included minimized functionality, accessibility features and simplified interface designs and structure. They also incorporated some features that the user could customize. Their conclusion is that they produced a system that was more usable (for the older user) than the standard packages available. They admit that more experienced users would need much greater functionality. In their design study, the design approach "Radically Simple", used in the development of the Cybrarian system, is discussed. Ironically the methodology is considered to create complexity itself as the designer attempts to increase any higher level of functionality. They suggest a layered approach may facilitate this. They admit these packages are usually marketed on increased functionality not less.

Both Hawthorn and those working on the Cybrarian project have noted the difficulties in the age gap between the designer and the older person. Even a middle-aged designer tends to make assumptions about older people which do not reflect the true requirements. Hawthorn insists that being informed of the difficulties is no substitute for first-hand experience (Hawthorn 2006). In her book Ageing for Beginners (Stott 1981) the author Mary Stott tells us ageing is relative in that no matter what age you are, you consider anyone 15-years-older as old. Regardless of what your age you still look out at the world through the same eyes and still feel the same person inside. Following this logic a 60-year old does not regard themselves as old and would consider someone aged 75 as old.

Gregor et al. (2002) concentrate on a different approach to deal with the diverse nature of the users and the dynamic nature of their requirements. They suggest an approach where, unlike the traditional method of seeking similarities amongst the users, the designer would seek out the differences. Since the user group is perhaps the most diverse they suggest that more research is required into structuring this 
approach. They also focus on the dynamic nature of the user requirements, the change over time, perhaps even over the span of the day or the changing environment of the user. It is suggested that, if this approach was to be taken, the resulting interface produced should be one that can accommodate the variety of needs and be adaptable to the situation and context. They also add that users should be able to personalise the interface. However, to allow personalisation of the interface can under certain circumstances also prove to be problematic. First if a service solution is designed for a SMART Home environment through which a district nurse or other professional care provider is able to monitor the patient in both the individuals' homes and remotely, then if personalisation/tailoring of the interface by the client is permitted, you automatically reduce the consistency of the interface for the professional carer across their case load, which as a consequence will cause increased search times and higher error rates when using the system in the individual clients' homes. This is the same reason behind large organisations insisting on having a common desktop environment to ensure consistency of the user interface across the organization. Second, with cognitive decline as a result of the onset of dementia, the end user will naturally become confused, and allowing continued personalisation of the interface for this type of end user, when they need more consistency not less, particularly with regard to colour usage and placement of navigation elements, will only add to their confusion.

The "User Sensitive Inclusive Design" (USID) methodology discussed by Gregor et al. claims that it may prove to be a useful approach to the problem. USID is suggested by Newell and Gregor (2000) as an extended form of User-Centred Design, where User-Centred Design is a common, standard approach to design in the HCI discipline. The original rationale of USID is based on the inclusion of disabled users, to help produce systems which can facilitate more universal access. It is referred to as sensitive rather than centred to reflect the diversity of the user group. It is difficult to represent the entire group completely. The inclusive nature of the design technique is emphasised to suggest that it is not possible to be truly universal, and they argue that universal design may not always be appropriate. This technique involves the designer attempting to facilitate all the possible users in the group. This will mean different approaches are required for requirements-gathering and other aspects of the design process.

\subsubsection{A Broader Technology-Related Perspective}

Up until 2003 most of the research and work in the topic area of design of interfaces for ageing people concentrated on Internet accessibility and web design (Hawthorn 2003), substantiated in the preliminary searches, which returned a high proportion of results regarding web design for older adults. Numerous guidelines and some legislation regarding the provision of accessibility to web sites for older and disabled adults are in place both in the UK and worldwide. Less work, however, has been done in the software and systems context, with regard to their interface design. Relentless advancements in technology have lead to advances in areas of ubiquitous 
and pervasive computing and heightened awareness in their application in the role of assistive technologies in the home context. These technologies will, in the very near future, be commonplace and whereas the active pursuit of purchasing technology may be avoided by elderly people today, the pervasive nature of these future developments will not be as easily avoided. When analogue television becomes obsolete, we will be forced to become users of digital TV. Currently, in the UK the Government is not only under pressure to fund state pensions for increasing numbers of retiring workers but also facing a healthcare financial crisis. Already care has been directed towards "in place" (in the home) solutions. The cost of care provision for persons living at home is a fraction of the cost of hospitalisation or institutional care. The 2001 Census revealed that there are approximately six million unpaid carers in the UK; these and other related statistics can be viewed at www.statistics.gov.uk. Consequently, ICT solutions are being sought.

It is reasonable to assume, as does Mynatt et al. (2004), that the general acceptance of sophisticated interface systems may stem from the development of a solution or integrated set of systems for the older user, and the need to facilitate independent living. They examine various technologies and their usefulness at Georgia Institute of Technology under the "Aware Home Research" initiative. In the Aware Home, technological support of the basic functions for living, referred to as ADLs (activities for daily Living) (Onn and Jin 1999), is the basis for the systems under investigation. They concentrate on three areas: overcoming the physical effects of ageing, the decline in cognitive ability (in particular loss of memory) and the support of the care network. With this and all of the discussed technologies, privacy, ethics and control are cited as concerns by the older people involved in this study.

The first generation of the assistive devices were primarily aimed at monitoring health and gave priority to the main preventable causes of elderly needing hospitalisation namely accidents and particular falls. Many homes have a now familiar alert system to call for help by activating a panic button. Falls are not only a common cause of death in older adults, but may bring on other conditions such as hypothermia or chest problems which cause death. Falls also cause a great deal of anxiety and fear after the event. People are afraid of falling again and so their normal life activities are affected. Those people who lay for an hour or more were 50\% more likely to die within the next 12 months (McKenna et al. 2006). Blyth et al. (2005) challenge the focus of this first generation approach and call for "Socially Dependable Design". They suggest that the issue should be approached from a social aspect, incorporating social contacts and networks around the application of technology. They observe that much of the work done concentrates on the computer. While ergonomic design is an important facet and indeed requirement for universal inclusion, social facets such as improving quality of life should be addressed in the application of technology in the home of the older person. Through their research Blythe et al. draw attention to the evidence gathered in the interviews conducted which find that personal contact was very important to the older person. Their need for contact was demonstrated as false alarms, where the older person "accidentally" set off their alert button on a regular basis in order to talk to the warden of their fold or sheltered housing scheme. They also highlight that independence is viewed differently by the two groups of people involved, i.e. the health worker viewed the input 
device which calls for help as providing independence but the quoted statistics indicated that the older user viewed not wearing it as independence. While HCI can play a part in the design of the fall detection and monitoring systems that are expected to be widely available in the near future, HCI can also play a part in socially grounded systems. Attention is also drawn to the overarching issues of privacy, liability and freedom of choice, which are all valid and important issues that surround this topic area. The researchers argue that we may be in danger of attempting to off-load our responsibilities of care onto technological devices. Their "Net Neighbours" scheme is given as an example of "Socially Dependable Design". This socially dependable design paradigm depends on human volunteers; the statistics show the decline in voluntary work. They argue that systems which allow volunteers to give up smaller chunks of time and provide the service from, for example, their work area could be implemented.

While it is true many older people live alone, many also have a complex care system surrounding them. Different friends and family members, as well as official health care workers, may all be involved to a greater or lesser degree. This can be quite complex and in order for a carer to be productive he must ascertain what the current situation is, e.g. has the person had lunch yet? Did someone else wash sheets? The older person is the centre of such a network and so a system which helps co-ordinate care could help reduce strain on that older person is discussed by Consolvo et al. (2004). This research focuses primarily on the role of technology to assist the carers of the older person. It does suggest that pervasive technologies could play a major role in alleviating the stresses and miscommunication within the group of carers and the older person themselves; a system where the cognitive load of the older person is decreased. The issues of privacy and respect will become increasingly important as these new technologies advance from the first generation monitoring systems to those systems, which enable other access to the person's data, or perhaps vision-based sensing systems. The danger of systems controlling an older person's environment is the dependence the person may have on the technology and its reliability.

Ho et al. (2005) found in their studies that older people had less confidence in their own judgement and so were more reliant on the decisions made by the technology. They conclude that this trait in the older user must be factored into design. The older user is less likely to pick up on an error due to the software or the technology and would be more likely to blame themselves, if something was wrong. This could make them vulnerable if the context where this technology was used was a decision making system, e.g. monitoring medication intake.

Other researchers in the field look to technology in the home to help promote healthy behaviour, rather than a medical or environmental control system. Intille's research suggests using the emerging technologies of context-aware computing and mobile communication to create an atmosphere to encourage healthy behaviour patterns (Intille 2004). Work has already been done on projects that encourage walking activity and on those which provide information at what is called "the point of decision making" as a feature, which can aid those with memory impairment.

Perry et al. (2004) examine the Millennium Home system, and is set in the context of a healthy older user who may develop conditions later in life. The system 
employs multimodal interaction and aims, primarily, to provide "context sensitive" appropriate two-way communication that does not require the person to wear an input device. As discussed earlier the wearing of such a device can be viewed as a diminishment of the person's independence rather than the facilitator of independence as intended. Perry et al. base their theories regarding the design of interfaces for such systems on those of forerunners, who state that the interface is the crucial part of any such system. They suggest that as speech and vision are the most natural forms of communication these modes are therefore an obvious choice for user interfaces. They argue that "natural and context sensitive interaction" can be achieved by employing multimodal forms of interactions. They examine the interaction value of the different modes themselves and the trade-offs between them, e.g. auditory signals or instructions are only available temporarily so may be most appropriate for alarms or to draw attention (The home environment can be full of distractions.) Written text is there to be viewed for a longer period of time as an advantage to those with lower cognitive abilities. The mode of the interaction is also dependant on the type of content and form of information trying to be conveyed. They point out difficulties in incorporating various modalities in a design, mode-switching and mode-mapping; the various modes must follow the same rules, paths and expected sequences, etc. They also argue that mode switching can help allow for the dynamic nature of this user group's requirement. This may imply that this type of design is by default, attractive to all users and can promote universal inclusion. However they cannot substantiate their hopes that it allows for the entire diversity of the users group. The interactions took place via telephone (speech lists and button selection), $\mathrm{TV} / \mathrm{monitor}$ screen (menu and remote control) and loudspeakers, sensors, voice recognition input. Interactions were designed on the basis of physical and activity context, urgency and interaction history, as well as allowing for physical limitations and general cognitive decline. The researchers had recognised the issues of intrusion and privacy, user control and had considered these in the design. This is not a system tested beyond the laboratory conditions of the Millennium Home itself. Introduction on a general scale would have many issues to be examined, such as security. Perry et al. suggest that if some intelligence were incorporated into the system it would allow for further functionality and an improved system.

Experimental research has been done by Bickmore et al. (2005) into relational agents. Defined as "computational artefacts designed to build and maintain long term social-emotional relationships with users", relational agents are the subject of research on the periphery of this topic area, concentrating on promoting healthy behaviours. They have studied the effects of using these agents to promote healthy habits amongst older people. The have found that the relationship built up between the person and the agent has better results when compared to non-relational systems. They argue that this facet of the system made it more acceptable to the older person and that it may be beneficial in motivation and in reducing loneliness for the older person, as well as nursing care contexts.

A similar design approach to Bickmore et al. is suggested by Forlizzi et al. (2004) by researchers in assistive robotics at Carnegie Mellon University. "Ethnographic Design Research Methods" are those that involve viewing the older person, the 
technology and their activities as a system to better understand the dynamics of the person's environment. The study of the relationship formed between the person and products and activities is a similar idea to that of the use of relational agents. Both are socially based. The researchers found that older people are more likely to only want a product that fulfils a functional need, they keep items which help them retain a sense of independence and dignity, and they rank social activities as high priorities. They suggest an "Ecological" design technique which incorporates the three aspects of person, product and activity that could produce a better product. They insist that social elements should be included in the design process.

Of course although the home becomes a more important focus for the older person (Stott 1981), there are other environments in which older people use technology and experience difficulties with the interaction. Earlier the $e$-information kiosk was discussed where elderly people could access information at the post office using the stand-alone kiosks. Many older people wish to drive their car for as long as possible; the car is a sign of independence for many sections of the population, not only older people. However, older people are finding the information displayed on the dashboard more difficult to interpret. The increased availability of navigation systems too can be difficult for elders to interpret. May et al.'s paper (2005) researches this problem. Based on the fact that cognitive decline has a detrimental affect on a person's ability to find their way through a strange environment, May et al. investigating the problems for older drivers, with the interface of in-car navigation systems. Their findings were that incorporating landmarks along side distance information had a positive effect on both confidence and accuracy, for the older driver particularly. Their findings support some of the work discussed earlier. The technology was accepted because of its functional benefits. Visual display was enhanced by another mode of interaction, i.e. auditory prompts (older people require longer to take in visual information) and less complex displays improved performance. They conclude that their inclusive design technique will improve the usability of the system for all users.

A "person centred technology evaluation" by Bagnall et al. (2006) reported that many of the participants considered themselves lonely, surprising since they lived in shared accommodation. They did not choose to be lonely; they had etiquettes and social rules which meant they would not want to disturb each other after $6 \mathrm{pm}$ or when they had visitors. Bagnall et al. also focus on contexts where interaction with modern devices is difficult for the user. In particular they look at social contexts such as communication. E-mail was discussed earlier, but perhaps as a computerbased package rather than from its importance in social aspects of an older person's lifestyle. Mobile phones, chat rooms, gaming, etc. are all commonplace for younger users and yet many poor designs of hardware and software limit the accessibility of these social technologies for older users. This is particularly unfortunate since time and again throughout this review of the research and literature the work has all pointed to the increased need for social inclusion and the appreciation of the older population to social activities, as well as their acceptance of devices to facilitate this. The ethnographic research techniques employed by Bagnall et al. were introduced earlier in this review as a way of studying the needs of the older person through the 
study of the environment into which the system will fit. They studied the device's place in the home, the activity of contacting friends whether face-to-face or via other communication means, the timings associated with this and the system itself. They designed to overcome etiquette of older people and interface issues such as scrolling and sequencing of conversation. They designed a different type of computer gaming that did not involve the computer enforcing rules, etc. and noticed that the time spent socialising during the game was quite significant. They introduced an audio communication package to facilitate social interaction. They conclude, as do many of the previous papers, that the social requirements for elders are a very important part of the design process. They are a group that have a very different set of social interaction etiquettes from the younger generation.

\subsubsection{Specific Interface Design Issues for People with Dementia}

The loss of short-term memory in the elderly as a result of a cognitive disability, such as dementia, is a problem for the person and for their family and carers. Social activities and interactions become difficult, especially as their condition progresses, as these activities and interactions require a functioning short-term memory for effective participation.

Emerging technologies have the potential to play an important role in improving the quality of life for people with dementia. To achieve this potential the design and development of user interfaces, which very often act as a barrier to people with dementia, is overcome.

One of the biggest problems facing developers of assistive technologies for intended use by the elderly or those with a form of physical or cognitive impairment are issues relating to the usability of the user interface. This issue is further complicated by the largely differing needs exhibited by the end user along with the necessity of adaptation to generate a personalised, user-specific assistive environment (Hariz et al. 2007).

Today's technology features state of the art interface solutions, such as touch screens, styli and hand/voice recognition as well as standard WIMP (Windows Icon Menu Pointer) interfaces (Abrams et al. 1999). All of the aforementioned technologies potentially complicate the development of a user interface given the vast range of functionalities that they can support. For example, a WIMP interface on a touch screen monitor decreases the system's usability because the menu's hit area is so small and the user's finger is not as precise as a pointer.

Alm et al. (2004) states that computers can be used as a cognitive prosthesis, which can help augment human intellect. A cognitive prosthesis should provide a compensatory strategy for people with dementia which, when added to their environment, increases their ability to function (Alm et al. 2004).

\subsubsection{Dementia in User-Centred Design}

Despite the increasing number of dementia sufferers, it is still common that a range of research excludes this group (Savitch and Zaphiris 2005). There is, however, a 
growing recognition that people with dementia should participate in research; as such people with dementia are being included in the design, development and evaluation of the services they use. The methodology of this research should focus on the participant's strengths. The feasibility of some methods involved, such as storyboarding, should be considered. Stalker et al. (1999) states that questions themselves can be threatening to someone with cognitive impairment. Bamford (1998) also suggests that the following Table 11.1 should be taken into consideration:

Table 11.1 Considerations when interviewing people with dementia

1. Family carers and staff may feel the need to be present and this may confound the validity of response

2. People with cognitive impairments function best in familiar surroundings

3. People with cognitive impairments can most easily comment on their immediate surroundings

4. People with cognitive impairments may need the aid of stimulus materials to discuss abstractions

Researchers and interviewers should note that when asking someone with dementia a question, that it is not inconceivable that the person with dementia is concerned with giving the correct answer, when in actual fact there is no correct answer.

When considering the design and usability of a user interface for people with dementia, it is imperative to keep the interface distinctive, familiar and legible. This will enhance the feeling of familiarity that a person with dementia needs.

\subsubsection{Previous Research for ICT and People with Dementia}

There have been various studies undertaken to provide computer-based help for persons with dementia, these range from personalised web pages to interactive games or reminiscence scrapbooks. While these systems and services are widely available for people without a cognitive disability, the development and adaptation for persons with dementia remain a problem.

Alm et al. undertook a pilot study that presented people with dementia with a "Reminiscence Scrapbook". The aim was to determine what multimedia components would be best to present to the person with dementia. These included text, video, pictures and music/sound. The general finding of this study was that the multimedia presentation interested and motivated the persons with dementia. The feedback for the system was constructive and encouraging. Staff and carers were unable to identify anything they did not like, however one patient did say they did not like something about the system, but when questioned further they were unable to elaborate. Carers also believed that the choice of material prompted the patients to speak more than usual. In relation to the technology used, everyone found the use 
of the touch screen to be beneficial. One carer suggested that the option to customise the interface would be preferable (Alm et al. 2004).

\subsubsection{Development of GUIs (Graphical User Interfaces) for People with Dementia}

Before embarking on an entirely new concept for the design of interfaces for use with dementia, it is useful to consider established approaches to date. Although these may not be the end result for the target cohort, they should be considered to be generic enough to at least be considered as a starting point upon which further changes may be made.

One of the fundamental standards of interface design is that of psychologist Paul Fitts, commonly known as Fitts' Law. This states that the time taken to move from a starting point to the target depends on two factors: the distance to, and size of, the target (Fitts 1954). By following the principles of this law, designers are advised to make the clickable icon a reasonable size. Not only does this law help us determine the size of the icon, but also their position on screen. For example buttons positioned on the corners of the screen are more efficient because it reduces the possibility of the user overshooting the target (Hale 2007). Today's technologies have come a long way since the days of Paul Fitts. Fitts' Law provides us with an excellent approach in developing WIMP interfaces. Nevertheless, the time taken to move from a starting point to a target becomes irrelevant, if a touch screen or styli is used.

Another law is Hick's Law, which states that the time taken for a user to make a decision is determined by the number of choices they are presented with. The user does not consider each option one-by-one, but instead they sub-divide the options into categories. Users will make a quicker decision from a list of ten options than two lists of five. This law provides us with a good platform from which we can develop menu structures. Nevertheless, when developing interfaces for assistive technologies, we have to consider the disability of the end user. A cognitive disability, such as dementia, will mean the users may become confused if too many options are presented at once, however, if not enough options are presented then the user will have to burrow their way down through various different menus to reach the service they require (Burns et al. 2008).

When developing a system that will be in continuous daily use, it is imperative to include the end user throughout the technology development cycle and most importantly the GUI. If an end user cannot be relied upon to provide constructive feedback then a qualified professional should be consulted in conjunction with them. For example, if the system is for a patient with mild dementia, then their feedback may fluctuate. In this case their carer should be consulted.

\subsection{Other Issues}

Issues are raised such as privacy and confidentiality and the emotional needs of the older person in many, if not most, of the research papers reviewed for this chapter. Older adults are in a more vulnerable position than most, and their privacy must be 
respected. They must at all times be afforded the same rights as other user groups, and the tendency to treat them as one would treat a child must be avoided. Their personal details and medical records are confidential and must remain confidential. Systems that are put in place, to aid the daily living of the older adult, must ensure that they do not compromise the rights of the individual in the pursuit of a solution. The question of independence or perceived independence is also a major issue. It is important that older people feel their independence is not being diminished by a system. It is vital to the acceptance that the person remains in control of his environment.

\subsection{Discussion and Conclusion}

The material reviewed has naturally lent itself to be categorized into five areas that have been titled: age-related issues, special requirements of the user group, emerging approaches, a broader technology-related perspective and specific interface design issues for people with dementia.

With regard to the age-related issues the reviewed papers have dealt with the physical and psychological age-related issues that should be considered during interface design. Zajicek discusses the problems of failing eyesight, hearing and memory loss. She suggests that a different approach to interface design is required to mitigate for the older person's loss of investigative learning techniques. The motivations of the older person are examined, finding convenience to be less important to this user than to younger groups of users. Reduced functionality is her recommendation to simplify the human-computer interactions. Hawthorn and Van Horen concentrate on the physical age-related issues. Their suggestions are for simplified structure, contrast between text and background, increased text and target sizes. Van Horen also suggests segmentation and presentation of most informative information first. Julie Jacko et al.'s paper concentrates on feedback and the advantages of using multimodal feedback are discussed. Her findings suggest auditory feedback to be the most beneficial and Hawthorn recommends using lower frequency sounds for this user group. The papers in this section also suggest that experienced computer users will also suffer the same age-related issues as novice users.

With regard to the special requirements of the user group the reviewed papers discuss acceptance, diversity, appropriate mental model, information gathering difficulties and issues relating to older peoples' attitudes and etiquette. As part of her results in investigations involving the use of PDAs, Wright concludes that acceptance of technology by the older user is evident. The greater diversity of this group compared to younger user groups is highlighted by the work of Zajicek and Brewster. They also recommend the use of a more sensitive, social approach when interacting with the user and the need for the use of appropriate mental models. Eisma also found the need for a social approach to the user and highlights the difficulties in communications between user and the younger designer. Eisma also suggests use of carefully structured questionnaires to force committal from the user and to improve the quality of results. Eisma's main recommendation is for the use of small focus groups of approximately three users, or even one to one interviews 
during requirements gathering. This is reiterated in the work of Lines and Hone who also recommend small structured focus group work.

With regard to the emerging approaches, Hawthorn's paper recommends the reduction of functionality to accommodate the older person's needs. Dickinson et al. found that using a simplifying strategy in their approach to design caused difficulties and admitted that the resulting lack of functionality affected the acceptance of the product for more experienced users. Gregor et al.'s paper focuses on the need to design for the dynamic nature of the user requirements, changing perhaps daily or hourly. Gregor et al. suggest user-sensitive inclusive design, where USID is an adaptation to the standard User-Centred Design (UCD) approach which aims to seek diversity instead of similarity to promote inclusion.

From the broader technology-related perspective other technologies will impact in the daily life of the older person, whether they choose it or not, due to the increase in pervasive computing systems. Assistive living devices will become more commonplace especially in view of the ageing population and the associated healthcare burden. Mynatt et al. suggest that the trigger for more wide spread use of assistive devices may stem from their development for use in the area of elder healthcare. Blyth et al.'s paper suggests we are in danger of "off-loading" our responsibility for elder care to technology and we should use a socially dependable approach to design. Consolvo et al. focus on the role of technology in the care network of the elderly person. An investigation into the Millennium Home and context-aware computing features in the work of Perry et al., where they argue that multimodal forms of interaction are required in a context-sensitive environment. The researchers in the papers featured in this section also point out the overarching issues of privacy, security, liability and over-dependence. While most of these papers research homebased technology, May et al. examine improving the interaction of the older driver with the car-navigation system. They find evidence to support the suggestion that older people require longer to decipher information and suggest "Land marking" can aid understanding for all but especially the older users. Combining auditory prompts was also found to increase the usability. Forlizzi et al. apply an ethnographic approach when designing a product for the elderly. They argue that this approach can produce a better product as it involves studying the "ecology" of the person, the product placement and the activities involved. Bagnall et al. also used ethnographic research techniques to aid design of their system. They concluded that the social interaction facilitated by the system was as important a requirement as other more functional requirements. They also reported that the user group operates under a very different set of social rules and etiquette than younger user groups.

With regard to specific interface design issues for people with dementia, including persons with dementia to assist in guiding the development of assistive technologies is something that should be pursued to its fullest extent. This inclusion encourages the development of usable, familiar and tailored assistive technologies. Current strategies for user-centred design may be more focused on persons without a cognitive disability, however, work by Bamford and Stalker has provided a clearer methodology from which to carry out user-centred design with persons with dementia. 
Technology can be used as a valuable tool for persons with dementia; however, the effectiveness of the technologies relies on the ability of the end user to use it. As mentioned above, the usability of the user interface is one of the major factors in the slow uptake of assistive technologies for persons with dementia. The current concepts of user interface design provide a sound basis from which to work from. However, these concepts should be tweaked and reworked to suit both the technologies and end user.

From the research it would appear that there are many valid age-related issues that affect the interaction of older people with technology. These are not only physical but also psychological and motivational issues that are directly due to age. These issues map to different aspects of the system and the interface. Physical issues have a direct relation to the physical elements of the interface, e.g. font size and contrast, while psychological and motivational issues have more bearing on the higher level design structures of the interface and the system functionality.

Some special requirements are not a physical symptom of ageing but are unique to this group. Many of the researchers have made mention of the wide diversity which exists within the user group and how the traditional methods of design do not cater for it and much of the basic understanding deficits reported in the research have been attributed to the user applying an incorrect mental model.

Generally we would accept that older people are quick to alienate themselves from technology, but research has shown that the group is not adverse from using new technology. Given the right motivation and circumstances the user group has proven keen to embrace emerging approaches in technology. One aspect that would seem to separate this group of users from all others is the great emphasis which is put on social factors. Perhaps it is because these users have trodden many paths, seen fads and fashions come and go and now have a deeper understanding of what is important in their lives, that they choose to prioritise social interaction above all else. This different approach itself can cause a barrier between them and the system designer. In the emerging approaches papers, some researchers approached the problem by reducing the functionality of present systems. They judged this to have limited success as experienced users of those systems were frustrated by the basic versions. Other emerging approaches concentrated on the treatment of the user rather than attempting to adapt an existing system. This treatment of the user called USID suggested different approaches and techniques for requirements gathering and other face-to-face time with the user group. The major shift towards designing for diversity rather than trying to find the common ground is also part of this approach.

Excluding a group of society from enjoying the benefits of technology is an issue of social inclusion. However, the problem is not restricted to computers and has wider implications. Elder healthcare could be delivered more efficiently and more cheaply if the problem could be overcome. The research involving applications in this area emphasises the importance of user involvement and the importance of allowing a person to remain in control of their environment. They call for socially aware computing for these users.

Some may argue that computer interaction will not be a problem for the elder person of the future, given their current exposure to technology, however, research 
has proven that even those who were considered to be computer literate experienced these difficulties. A solution to this problem will therefore not only help the older population of today but also the generations to come.

Acknowledgements The TRAIL (Technologies for Rurality, Ageing and Independent Living) lab represents the development of innovation and research thinking in Northern Ireland to support independent living across several key disciplines including business, information and communication technologies, occupational therapy, art, health care, social care and clinical medicine. Based at the University of Ulster, TRAIL is focused on supporting this diverse set of stakeholders as we develop new technologies, research perspectives, processes and integrated service solutions that deliver real value to our users, the ageing people in the North of Ireland and further a field across Europe.

\section{References}

Abrams, M., Phanoutiou, C., Batongbacal, A. et al. (1999) UIML: An appliance-independent XML user interface language. Computer Networks, 31(11):1695-1708.

Alm, N., Astell, A., Ellis, M., Dye, R., Gowans, G., Campbell, J. (2004) A cognitive prosthesis and communication support for people with dementia. Neuropsychological Rehabilitation, 14(1/2):117-134.

Alzheimer's Research Trust. (2009) http://www.alzheimers-research.org.uk/info/statistics, accessed 8 January 2009.

Bagnall, P., Onditi, V., Rouncefield, M., Sommerville, I. (May 2006) Older people, technology and design: A socio-technical approach. Gerontechnology, 5(1):46-50.

Bamford, C. (1998) Consulting people with dementia. Cash Care, Spring, 2.

Banks, J., Smith, Z., Wakefield, M. (2006) The Distribution of Financial Wealth in the UK: Evidence from 2000 BHPS Data, p. 11. Available at: www2.warwick.ac.uk, accessed on 5 December 2006.

BBC News (2007) Source: http://news.bbc.co.uk/1/hi/health/395143.stm, Accessed 27 March 2007.

Bickmore, T.W., Caruso, L., Clough-Gorr, K., Heeren, T. (2005) 'It's just like talking to a friend' relational agents for older users. Interacting with Computers, 17:711-735.

Blyth, M., Monk, A.F., Doughty, K. (2005) Socially dependable design: The challenge of ageing population for HCI. Interacting with Computers, 17:672-689.

Burns, W., Nugent, C., McCullagh, P., Zheng, H., Finlay, D., Davies, R., Donnelly, M., Black, N. (2008) Personalisation and configuration of assistive technologies. Engineering in Medicine and Biology Society, 30th International Conference of the IEEE, 20-25 August, pp. 3304-3307.

Consolvo, S., Roessler, P., Shelton, B.E., LaMarca, A., Schilit, B., Bly, S. (2004) Technology for care networks of elders. IEEE Pervasive Computing, 3(2):22-29.

Dickinson, A., Newell, A.F., Smith, M.J., Hill, R.L. (2005) Introducing the Internet to the over 60s: Developing an e-mail system for older novice computer users. Interacting with Computers, 17:621-642.

Digital Inclusion Panel. (2004) Enabling a Digitally United Kingdom, a Framework for Action. The Cabinet Office, London. http://www.cabinetoffice.gov.uk/publications/reports/ digital/digitalframe.pdf Accessed 18 October 2006.

Eisma, R., Dickinson, A., Goodman, J., Syme, A., Tiwari, L., Newell, A.F. (2004) Early user involvement in the development of information technology-related products for older people. Universal Access in the Information Society, 3:131-140.

Eurostat. (2002) NewCronos Database (Health and Safety), statistics - Key Data on Health 2002. Eurostat Morbidity Seminar, London.

Fitts, P.M. (1954) The information capacity of the human motor system in controlling the amplitude of movement. Journal of Experimental Psychology, 47(6):381-391. 
Forlizzi, J., DiSalvo, C., Gemperle, F. (2004) Assistive robotics and ecology of elders living independently in their own homes. Human Computer Interaction, 19:25-29.

Gregor, P., Newell, A.F., Zajicek, M., 2002, Designing for dynamic diversity - Interfaces for older people. ACM SIGACCESS Conference on Assistive Technologies, Proceedings of the Fifth International ACM Conference on Assistive Technologies, Solutions for Aging, pp. 151-156.

Hale, K. (2007) Visualizing Fitt's Law, October 3rd, 2007; http://particletree.com/features/ visualizing-fittss-law Accessed 2 November 2008.

Hariz, M., Renouard, S., Mokhtari, M. (2007) Designing multimodal interaction for assistive robotic arm. IEEE 10th International Conference on Rehabilitation Robotics, Noordwijk, The Netherlands.

Hawthorn, D. (2000) Possible implications of ageing for interface designers. Interacting with Computers, 12:507-528.

Hawthorn, D. (2003) How Universal is Good Design for Older Users. CUU 2003 November 10-11, Canada.

Hawthorn, D. (2006) Enhancing the contribution of older people to interface design. Gerontechnology, 5(1):4-14.

Ho, G., Wheatley, D., Scialfa, C.T. (2005) Age differences in trust and reliance of a medication management system. Interacting with Computers, 17:690-710.

Hopkins, H. (2007) Hitwise Intelligence. Source: http://weblogs.hitwise.com/heatherhopkins/2007/05/54_increase_put_silver_surfers.html, accessed 18 May 2007.

Intille, S.S. (2004) A new research challenge: persuasive technology to motivate healthy aging. IEEE Transactions on Information Technology in Biomedicine, 8(3):235-237.

Jacko, J., Emery, V.K., Edwards, P.J., Ashok, M., Barnard, L., Kongnakorn, T., Moloney, K.P., Sainfort, F. (July-August 2004) Effects of multimodal feedback on older adults' task performance given varying levels of computer experience. Behaviour \& Information Technology, 23(4):247-264.

Jeffrey, S. (2003) Over 60s Reach for the Mouse, July 8 2003, www.guardian.co.uk, accessed on 18 October 2006.

Keates, S., Clarkson, P.J. (2003) The Design of Kiosks for Providing Access to E-Information for Older Adults, www.eng.cam.ac.uk, accessed 18 October 2006.

Lines, L., Hone, K. (2004) Eliciting user requirements with older adults: Lessons from the design of an interactive domestic alarm system. Universal Access in the Information Society, 3:141-148.

May, A., Ross, T., Osman, Z. (2005) The design of next generation in-vehicle navigation systems for the older driver. Interacting with Computers, 17:643-659.

Mynatt, E., Melenhorst, A., Fisk, A., Rogers, W. (2004) Aware technologies for ageing in place: Understanding user needs and attitudes. IEEE Pervasive Computing, 3(2):36-41.

McKenna, S.J., Marquis-Faulkes, F., Newell, A.F., Gregor, P. (2006) Requirements gathering using drama for computer vision-based monitoring in supportive home environments. Technology and Disability, 17(4):227-236.

Newell, A.F., Gregor, P. (2000). User sensitive inclusive design, in search of a new paradigm. Proceedings on the 2000 Conference on Universal Usability, pp. 39-44, November 16-17, 2000 (J. Scholtz, J. Thomas, eds.).

Norman, D.A. (1992) The Psychology of Everyday Things. Basic Books, New York.

Onn, I.L.Y., Jin, P.C.W. (1999) Assessment of the Elderly Patient. The Singapore Family Physician, 25(2), 1999. Available at: http://www.cfps.org.sg/sfp/25/252/articles/e252008.html, accessed 11 July 2006.

Perry, M., Dowdall, A., Lines, L., Hone, K. (2004) Multimodal and ubiquitous computing systems: Supporting independent-living older users. IEEE Transactions on Information Technology in Biomedicine, 8(3):258-270.

World Health Organisation. (2005) Preventing Chronic Diseases - A Vital Investment. Available at: http://www.who.int/chp/chronic_disease_report/contents/en/index.html. Accessed 2 January 2010. 
Savitch, N., Zaphiris, P. (2005) An investigation into the accessibility of web-based information for people with dementia. Eleventh International Conference on Human-Computer Interaction, Las Vegas, July 2005.

Schneiderman, B. (1996) Designing the User Interface: Strategies for Effective Human-Computer Interaction. Addison-Wesley Publishing Company, Reading, Massachusetts..

Stalker, K., Gilliard, J., Downs, M.G. (1999) Eliciting user perspectives on what works. International Journal of Geriatric Psychiatry, 14:120-134.

Stott, M. (1981) Ageing for Beginners. Oxford, Blackwell.

Stuart-Hamilton, I. (1994) The Psychology of Ageing: An Introduction, 2nd edn. Kingsley, London.

van Horen, F., Jansen, C., Noordman, L., Maes, A. (2005) Manuals for the elderly: Text characteristics that help or hinder older users. IEEE International Professional Communication Conference Proceedings, Santa Fe, New Mexico.

Weiser, M. (September 1991) The computer for the 21st century. Scientific American, 265(3): 94-104.

Wright, P., Bartram, C., Rogers, N., Emslie, H., Evans, J., Wilson, B., Belt, S. (2000) Text entry on handheld computers by older users. Ergonomics, 43(6):702-716.

Zajicek, M. (2001) Interface Design for Older Adults. WUAUC'01, May 22-25, p. 60.

Zajicek, M., Brewster, S. (June 2004) Design principles to support older adults. Universal Access in the Information Society, 3(2):111-113. 